\title{
The Investigation of the Physical and Performance Effects of High-Intensity Interval Training (HITT) on Sedentary University Students
}

\author{
Ali Erdem Cigerci ${ }^{1} \&$ Harun Genc ${ }^{2}$ \\ ${ }^{1}$ School of Physical Education and Sports, Kastamonu University, Kastamonu, Turkey \\ ${ }^{2}$ School of Physical Education and Sports, Bingol University, Bingol, Turkey \\ Correspondence: Ali Erdem Cigerci, School of Physical Education and Sports, Kastamonu University, \\ Kastamonu, 37100, Turkey. E-mail: aecigerci@kastamonu.edu.tr
}

Received: January 15, 2020

Accepted: February 27, 2020

Online Published: June 21, 2020

doi:10.5539/ies.v13n7p57

URL: https://doi.org/10.5539/ies.v13n7p57

\begin{abstract}
The aim of this study was to examine the physical and selected performance characteristics of 9-week High-Intensity Interval Training (HIIT) on sedentary university students. Participants were separated two groups as HIIT and control group (CG). HIIT group applied training 3 times a week for 9 weeks. CG was not applied any training. Before and after HIIT training program, the subjects were applied to age, height, body weight (BW), body mass index (BMI) tests for physical parameters and standing long jump (SLJ), vertical jump (VJ), 10-20 m sprint, $\mathrm{T}$ agility test (TAT), star excursion balance test (SEBT), running-based anaerobic sprint test (RAST) for performance parameters. Multiple analysis of variance (MANOVA) was used to analyze of inter-group, intra group and the effect of training in repeated measurements. Bonferroni test was used for Post Hoc comparisons; the significance level was accepted as 0.05 . There was a significant difference in BW, BMI and all performance parameters in favor of HIIT group. HIIT provided effective development to physical and performance characteristics of university students.
\end{abstract}

Keywords: biomotoric analysis, healthy lifestyle, high-intensity interval training, university students

\section{Introduction}

The suggested level of physical activity (PA) to correct health risks for adult is equivalent to 150 min of moderate intensity continuous exercise (MICT) or 75 min per week of vigorous exercise (Garber et al., 2011). Physical activity is known to used for weight control and managing obesity (Chin et al., 2016; Shook, 2016; Verheggen et al., 2016). The greatest barrier to regular PA is seen as lack of time (Brownson et al., 2001; Sequeira et al., 2011; Stavrinou et al., 2019). Given the lack of available time for PA, it is of importance to determine the minimum exercise duration and frequency required to induce favorable physiological and psychological adaptations, especially in the general population (Stavrinou et al., 2019). So, high-intensity interval training (HIIT) seems to be effective in terms of time.

HIIT involves alternating short bursts of high intensity exercise with recovery periods or light exercise and including HIIT in a training programme implies that greater health-enhancing benefits could be gained in less time, making HIIT a more time efficient and attractive option (Weston et al., 2014). The purpose of HIT is to repeatedly stress the physiological systems that will be used during a specific endurance-type exercise (Daniels \& Scardina, 1984) to a greater extent than that which is actually required during the activity (Laursen \& Jenkins, 2002). Besides, HIIT is as efficacious a protocol at improving aerobic fitness as traditional endurance training despite the reduced time commitment (Batacan et al., 2017). HIIT also induces greater improvements in cardiorespiratory fitness than MICT in healthy, young to middle-aged adults (Bacon et al., 2013; Milanović et al., 2015). So, it can be understood that HIIT is an easily applicable training method for people at all fitness levels, as well as for people with special conditions such as obesity and diabetes and it can be also applied with all exercise models (running, walking, swimming, cycling, aqua etc.) (Akgül et al., 2017). The aim of this study is to examine the physical and physiological characteristics of 9-week HIIT on sedentary university students. 


\section{Methods}

\subsection{Participants}

Twenty-four (24) healthy male university students, aged $19.66 \pm 1.11$ years, voluntarily participated in the study. The students were divided into two groups as 12 HITT groups and $12 \mathrm{CG}$ at the beginning of the training period so that there was no difference in terms of physical and performance parameters. While HITT group were applied the HITT for 9 weeks, CG did not participate in any training. Besides, all subjects were asked to avoid challenging activities during the training. Signed informed consent from all subjects was obtained.

\subsection{Procedures}

The volunteer university students participating in the study were applied HIIT 3 times a week for 9 weeks. The program, which started with a 20 -second sprint in the first week, was increased to $30 \mathrm{~s}$ in the following weeks, and the total sprint time of individuals was increased. HITT group applied 30 seconds sprints at maximum capacity (20 s for week 1) also 3-4 minutes passive recovery sections between sprints. HITT were carried out in the athletics track under the supervision of the researchers and the training hour was 10:00 am for each training.

Table 1. 9-week HITT program (Allen et al., 2017)

\begin{tabular}{cccccccccc}
\hline \multirow{2}{*}{ Variables } & $1^{\text {st }}$ & $2^{\text {nd }}$ & $3^{\text {rd }}$ & $4^{\text {th }}$ & $5^{\text {th }}$ & $6^{\text {th }}$ & $7^{\text {th }}$ & $8^{\text {th }}$ & $9^{\text {th }}$ \\
& Week & Week & Week & Week & Week & Week & Week & Week & Week \\
\hline ST (s) & 20 & 30 & 30 & 30 & 30 & 30 & 30 & 30 & 30 \\
RC (min) & 4 & 4 & 4 & 4 & 3.30 & 3.30 & 3.30 & 3.30 & 3.10 \\
RP (Piece) & 5 & 4 & 5 & 6 & 6 & 6 & 7 & 8 & 8 \\
TST (min) & 1.40 & 2.00 & 2.30 & 3.00 & 3.00 & 3.00 & 3.30 & 4.00 & 4.00 \\
\hline
\end{tabular}

ST: Sprint time, R: Recovery, RP: Repetitions, TST: Total Sprint Time

In the study, before and after HITT training program the features of age, height, body weight (BW), body mass index (BMI) for physical measurements and the features of vertical jump (VJ), standing long jump (SLJ), 10-20 m sprint, T agility test (TAT), star excursion balance test (SEBT), running-based anaerobic sprint test (RAST) for performance measurements were obtained from all participants.

The height of the subjects was measured with Holtain brand stadiometer with a sensitivity of $0.01 \mathrm{~cm}$ in anatomical position (barefoot) and BW was measured with a sensitivity of $0.01 \mathrm{~kg}$ in anatomical position (barefoot). BMI was calculated by "BMI = weight $(\mathrm{kg}) /(\text { height })^{2}$ " formula.

VJ and SLJ tests were applied as mentioned before (Kaplan et al., 2016; Krishnan et al., 2017). In 10-20 m sprint test, the subjects started the test from the starting line located 1 meter behind the starting photocell (Newtest 2000; Newtest Oy, Oulu, Finland), sprint tests were recorded through the photocells placed at 10th and 20th meter. Each student repeated the test twice and better one was recorded as "seconds". TAT, T-shaped in an area of $10 \mathrm{~m}$ length and $10 \mathrm{~m}$ length consists of 4 created contact points. The subject tried to complete this track moving in different ways and directions as soon as possible. In TAT the subjects run from the starting point to a sign cone $10 \mathrm{~m}$ away, went to second cone $5 \mathrm{~m}$ away by a side shuffle left. When the subjects touched the cone, they went by side shuffle to the cone $10 \mathrm{~m}$ away and then went by side shuffle back to the middle cone. The test was finished by back pedaling to the starting point (Asadi, 2016). Better of two trials was recorded as "seconds".

SEBT was performed with the participants standing in the middle of a grid formed by eight lines extending out at $45^{\circ}$ from each other. While the participant was in the center of the star and tried to reach the points in eight different directions, prepared in 45 degree increments with one leg (stable) and the other in the center of the circle. Both legs were tested to reach distances. Normalization was performed by dividing each excursion distance by a participant's leg length, and then by multiplying by 100 (Gribble \& Hertel, 2003). RAST consisted of 6 maximal efforts of $35 \mathrm{~m}$, separated by a passive recovery period of $10 \mathrm{~s}$. The time of each effort of $35 \mathrm{~m}$ was recorded using a system of photocells (Newtest 2000; Newtest Oy, Oulu, Finland) located at the beginning and at the end of the $35 \mathrm{~m}$. After the test, the peak power (PP), average power (AP), minimum power (MP) and fatigue index (FI) of subjects were calculated as mentioned before (Andrade et al., 2015).

\subsection{Statistical Analysis}

The data obtained from measurements of subjects were analyzed by IBM SPSS 22.0 statistical program. Descriptive statistics are categorized according to all students and groups. The pre- and post-test distributions of 
the variables were examined according to groups, the normality of the distributions and the homogeneity of the variance were determined by the Mauchly's Test of Sphericity and the Levene Test. Multiple analysis of variance (MANOVA) was used to analyze of inter-group, intra group and the effect of training in repeated measurements. Bonferroni test was used for intra-group analysis (Post Hoc comparisons), in the study the significance level was examined at 0.05 .

\section{Results}

Table 2. Descriptive statistics of participants

\begin{tabular}{|c|c|c|c|c|c|c|c|}
\hline Group & $\mathrm{N}$ & Variables & Average \pm S.D & Min. & Max. & & \\
\hline HITT & 12 & \multirow{2}{*}{ Age ( year) } & $19.71 \pm 0.99$ & 18 & 21 & & \\
\hline $\mathrm{CG}$ & 12 & & $19.42 \pm 0.97$ & 18 & 21 & & \\
\hline HITT & 12 & \multirow{2}{*}{ Height $(\mathrm{cm})$} & $181.28 \pm 7.07$ & 170.00 & 194.00 & & \\
\hline CG & 12 & & $176.71 \pm 8.32$ & 167.00 & 190.00 & & \\
\hline HITT & 12 & \multirow{2}{*}{ BW (kg) } & $73.35 \pm 8.41$ & 64.00 & 90.00 & & \\
\hline $\mathrm{CG}$ & 12 & & $68.14 \pm 8.74$ & 57.00 & 78.00 & & \\
\hline HITT & 12 & \multirow{2}{*}{$\operatorname{BMI}\left(\mathrm{kg} / \mathrm{m}^{2}\right)$} & $21.92 \pm 2.27$ & 18.50 & 25.20 & & \\
\hline $\mathrm{CG}$ & 12 & & $21.77 \pm 3.40$ & 18.30 & 27.30 & & \\
\hline \multirow{5}{*}{ Total } & \multirow{5}{*}{24} & & & & & Chi-Square $\left(X^{2}\right)$ & $\mathrm{p}$ \\
\hline & & Age ( year) & $19.66 \pm 1.11$ & 18 & 21 & 0.054 & 0.817 \\
\hline & & Height $(\mathrm{cm})$ & $179.76 \pm 7.62$ & 167.00 & 194.00 & 1.344 & 0.246 \\
\hline & & BW (kg) & $71.61 \pm 8.68$ & 57.00 & 90.00 & 0.947 & 0.331 \\
\hline & & $\operatorname{BMI}\left(\mathrm{kg} / \mathrm{m}^{2}\right)$ & $21.87+2.61$ & 18.30 & 27.30 & 0.201 & 0.654 \\
\hline
\end{tabular}

*p > 0.05; BW: Body Weight'; BMI: Body Mass Index

In Table 2, it is understood that there is no significant difference for all descriptive variables between groups before the training period $(\mathrm{p}>0.05)$.

Table 3. Comparison of physical features between groups

\begin{tabular}{cccccccc}
\hline Variables & N & Group & Pre-Test X \pm SS & Post-Test X+SS & In-group Change (\%) & Test*Group F & $p$ \\
\hline \multirow{2}{*}{ Height $(\mathrm{cm})$} & 12 & HITT & $181.28 \pm 7.07$ & $181.64 \pm 7.21$ & $0.36(0.19 \%)$ & 0.097 & 0.758 \\
& 12 & CG & $176.71 \pm 8.32$ & $177.00 \pm 8.16$ & $0.29(0.16 \%)$ & & \\
BW $(\mathrm{kg})$ & 12 & HITT & $73.35 \pm 8.41$ & $72.42 \pm 8.29$ & $-0.93(-1.27 \%)^{*}$ & 30.005 & $0.000^{*}$ \\
& 12 & CG & $68.14 \pm 8.74$ & $68.42 \pm 8.75$ & $0.28(0.41 \%)$ & & \\
BMI $\left(\mathrm{kg} / \mathrm{m}^{2}\right)$ & 12 & HITT & $21.92 \pm 2.27$ & $21.63 \pm 2.27$ & $-0.29(-1.32 \%)^{*}$ & 35.501 & $0.000^{*}$ \\
\hline
\end{tabular}

*p < 0.05; BW: Body Weight; BMI: Body Mass Index

Although there is no statistical difference in the height of the subjects, there is a significant difference in the BW and BMI characteristics between the pre and post-test measurements. However, when the changes in BW and BMI features of subjects are examined, it is seen that there is test*group interaction in both features and it is determined that the interaction in these parameters is caused by a significant decrease in the results of HIIT group. 
Table 4. Comparison of RAST between groups

\begin{tabular}{|c|c|c|c|c|c|c|c|}
\hline Variables & $\mathrm{N}$ & Group & Pre-Test $\mathrm{X}_{-} \mathrm{SS}$ & Post Test $\mathrm{X}_{\underline{+}} \mathrm{SS}$ & In-group Change (\%) & Test*Group F & $\mathrm{p}$ \\
\hline \multirow{2}{*}{ PP (Watt) } & 12 & HITT & $513.00 \pm 84.14$ & $538.07 \pm 85.54$ & $25.07(4.88 \%)^{*}$ & \multirow{2}{*}{23.715} & \multirow{2}{*}{$0.000^{*}$} \\
\hline & 12 & $\mathrm{CG}$ & $444.85 \pm 61.82$ & $449.71 \pm 60.85$ & $4.86(1.09 \%)$ & & \\
\hline \multirow{2}{*}{ AP (Watt) } & 12 & HITT & $474.28 \pm 84.59$ & $486.85 \pm 85.91$ & $12.57(2.65 \%)^{*}$ & \multirow{2}{*}{21.950} & \multirow{2}{*}{$0.000 *$} \\
\hline & 12 & $\mathrm{CG}$ & $395.14 \pm 61.03$ & $393.14+61.09$ & $-2.00(-0.50 \%)$ & & \\
\hline \multirow{2}{*}{ MP (Watt) } & 12 & HITT & $429.07 \pm 92.97$ & $433.64 \pm 92.92$ & $4.57(1.06 \%)^{*}$ & \multirow{2}{*}{19.158} & \multirow{2}{*}{$0.000 *$} \\
\hline & 12 & CG & $352.42 \pm 67.10$ & $353.14 \pm 67.87$ & $0.72(0.20 \%)$ & & \\
\hline \multirow{2}{*}{ FI (\%) } & 12 & HITT & $2.41 \pm 1.15$ & $2.70 \pm 1.16$ & $0.29(12.03 \%)^{*}$ & \multirow{2}{*}{9.351} & \multirow{2}{*}{$0.006^{*}$} \\
\hline & 12 & $\mathrm{CG}$ & $2.57 \pm 1.53$ & $2.71 \pm 1.51$ & $0.14(5.44 \%)$ & & \\
\hline
\end{tabular}

*p < 0.05; PP: Peak Power, AP: Average Power, MP: Minimum Power, FI: Fatigue Index

When the RAST measurements of the subjects are analyzed, it is seen that all of RAST values increase significantly in HIIT group. The test*group interaction in all parameters of RAST is statistically significant and the significance is due to the improvement demonstrated by HIIT group.

Table 5. Comparison of performance measurements between groups

\begin{tabular}{|c|c|c|c|c|c|c|c|}
\hline Variables & $\mathrm{N}$ & Group & Pre-Test $\mathrm{X} \pm \mathrm{SS}$ & Post Test $\mathrm{X} \pm \mathrm{SS}$ & In-group Change (\%) & Test*Group F & $\mathrm{p}$ \\
\hline \multirow{2}{*}{10 m SR (s) } & 12 & HITT & $1.50 \pm 0.11$ & $1.47 \pm 0.10$ & $-0.03(-2.00 \%)^{*}$ & \multirow{2}{*}{19.922} & \multirow{2}{*}{$0.000^{*}$} \\
\hline & 12 & $\mathrm{CG}$ & $1.55 \pm 0.08$ & $1.56 \pm 0.08$ & $0.01(0.64 \%)$ & & \\
\hline \multirow{2}{*}{20 m SR (s) } & 12 & HITT & $3.62 \pm 0.17$ & $3.52 \pm 0.16$ & $0.10(2.76 \%)^{*}$ & \multirow{2}{*}{12.976} & \multirow{2}{*}{$0.002 *$} \\
\hline & 12 & $\mathrm{CG}$ & $3.62 \pm 0.08$ & $3.66 \pm 0.07$ & $0.04(1.10 \%)$ & & \\
\hline \multirow{2}{*}{$\mathrm{SLJ}(\mathrm{cm})$} & 12 & HITT & $235.21 \pm 14.56$ & $240.71 \pm 13.10$ & $5.5(2.33 \%)^{*}$ & \multirow{2}{*}{13.076} & \multirow{2}{*}{$0.002 *$} \\
\hline & 12 & CG & $229.28 \pm 12.53$ & $231.00 \pm 10.11$ & $1.72(0.75 \%)$ & & \\
\hline \multirow{2}{*}{$\mathrm{VJ}(\mathrm{cm})$} & 12 & HITT & $29.71 \pm 5.48$ & $32.28+4.49$ & $2.57(8.65 \%)^{*}$ & \multirow{2}{*}{4.782} & \multirow{2}{*}{$0.041^{*}$} \\
\hline & 12 & CG & $24.85 \pm 2.67$ & $25.28 \pm 2.42$ & $0.43(1.73)$ & & \\
\hline \multirow{2}{*}{ TAT (s) } & 12 & HITT & $8.71 \pm 0.89$ & $8.52 \pm 0.41$ & $-0.19(-2.18 \%)^{*}$ & \multirow{2}{*}{5.365} & \multirow{2}{*}{$0.032 *$} \\
\hline & 12 & CG & $8.30 \pm 0.28$ & $8.58 \pm 0.27$ & $0.28(3.37 \%)$ & & \\
\hline \multirow{2}{*}{ SEBT } & 12 & HITT & $682.42 \pm 42.16$ & $694.21 \pm 38.41$ & $8.36(1.22 \%)^{*}$ & \multirow{2}{*}{10.497} & \multirow{2}{*}{$0.004 *$} \\
\hline & 12 & $\mathrm{CG}$ & $725.00 \pm 32.44$ & $720.42 \pm 27.87$ & $-4.58(-0.63 \%)$ & & \\
\hline
\end{tabular}

*p < 0.05; 10 m SR: 10 m speed run, 20 m SR: 20 m speed run, SLJ: Standing Long Jump, VJ: Vertical Jump, TAT:

T Agility Test, SEBT: Star Excursion Balance Test

When the performance parameters of groups are analyzed, it is seen that in all parameters, there is a statistically significant development in HIIT group and there is no significant difference CG. The differences between the groups appear in the post-test values and CG remain at a statistically worse value than HIIT group. In this regard, the test*group interaction for performance tests is statistically significant and the significance is due to HITT group.

\section{Discussion}

In this study, it was understood that in physical features parameters when there was no difference in the height of the subjects, BW and BMI values are seen as statistically significant and the significance was caused by a positive decrease in the results of HIIT group. According to the literature, there are some studies stating that regular physical exercises have positive effects on obesity, blood pressure, physical well-being, body fat and healthy life (Charach et al., 2004; Laaksonen et al., 2002; Ockene et al., 2004; Ryan et al., 1996). In a study which examined the effects of exercise intensity on cardiovascular health and total body composition, it was found that low-intensity exercises were significant on weight as a result of an 8-month exercise program that formed two groups of high and medium intensity (Gutin et al., 2002). As a result of the 6-week treadmill exercise in another study, a statistically significant decrease was observed in the weight of individuals from $76.8 \pm 12.5 \mathrm{~kg}$ to $75.0 \pm$ $12.0 \mathrm{~kg}$ after exercise (Szmedra et al., 1998). Besides, it was declared that while BMI of subjects decreased as statistically significant in 41.6-year-old women because of 12-week aerobic exercises 3 days a week (Amano et al., 2001), it was also said that 12-week HIIT had positive effects on BMI and anthropometric values of sedentary people (Kordi et al., 2013) and it was also said that HIIT was very effective on body composition of sedentary people in many studies (Allen et al., 2017; Khammasi et al., 2018; Miller et al., 2014). It was determined in the 
studies that there was a significant decrease in BW and BFP as a result of the breakdown of high amounts of calories during the training and the rapid metabolism that occurs (Bagger et al., 2003; Günay et al, 2000; Segal et al., 2004). So, it can be said that HIIT is a very effective training method for body composition and healthy lifestyle for sedentary people.

It was seen that RAST PP, AP, MP and FI values increased significantly in HIIT group and there was no significant change in CG and the significance was due to the statistically significant development shown by the HITT group. In a study by, HIIT training was applied to university students for 4 weeks and a significant increase in PP and AP values was detected (Naimo et al., 2015). In another study, a group of 20 women and 20 men underwent short-term HIIT training, and the tendency to increase in PP and MP was not significant (Astorino et al., 2012). However, unlike our findings, there was no increase in FI in these two studies. This can be explained by the fact that these two studies are shorter in duration than our study. Longer physiological stimulants through training can speed up the transport and elimination of lactic acid, thereby slowing the onset of fatigue.

When the results of the performance tests belonging to the groups are examined, when the results of $10-20 \mathrm{~m}$ sprint tests, VJ and SLJ, TAT and SEBT are examined, it is seen that there is a significant improvement in the experimental group, and there is no change in the control group. It was stated that there was a significant difference in the 10-meter running test and agility test average values HIIT group (Iacono et al., 2015). In another study, it was also reported that there was no significant difference between the agility test mean values in a study examining the effect of HIIT on seasonal performance in soccer players (Howard \& Stavrianeas, 2017). The reason for this may be due to the different load intensity in the training sessions applied in the studies. It was understood that the training that includes HIIT method improves VJ (Monks et al., 2017), jumping and sprint (Buchan et al., 2013; Kilit \& Arslan, 2019), balance (Bressel et al., 2014) and agility (Seo et al., 2019). On the other hand, the effects of HIIT is due, in part, to positive contribution of two metabolism to the energy demand (MacDougall et al., 1998; Rodas et al., 2000; Simoneau et al., 1987) which enhances the availability of ATP and improves the energy status in working muscle (Laursen \& Jenkins, 2002). It is important to use regular exercises that are performed as a form of physical activity to improve and maintain fitness, as well as regular training provides a decrease in BW and BFP.

\section{Conclusion}

With this research, it was tried to reveal the positive effect of HIIT on physical fitness parameters. Research in this field should be combined with research in the psychological and sociological field, and informative studies should be conducted to guide the society. The idea of how important active life is for general health today must be brought into community awareness. As a result; it can be said that HITT, which is applied 3 days a week for 9 weeks, provide positive physical and performance development to physical and performance characteristics of university students.

\section{References}

Akgül, M. Ş., Mitat, K., Gürses, V. V., \& Kürkçü, R. (2017). Yüksek şiddetli interval antrenman. Spormetre Beden Eğitimi ve Spor Bilimleri Dergisi, 15(2), 39-46. https://doi.org/10.1501/sporm_0000000306

Allen, N. G., Higham, S. M., Mendham, A. E., Kastelein, T. E., Larsen, P. S., \& Duffield, R. (2017). The effect of high-intensity aerobic interval training on markers of systemic inflammation in sedentary populations. European journal of applied physiology, 117(6), 1249-1256. https://doi.org/10.1007/s00421-017-3613-1

Amano, M., Kanda, T., Hidetoshi, U. E., \& Moritani, T. (2001). Exercise training and autonomic nervous system activity in obese individuals. Medicine \& Science in Sports \& Exercise, 33(8), 1287-1291. https://doi.org/10.1097/00005768-200108000-00007

Andrade, V. L., Zagatto, A. M., Kalva-Filho, C. A., Mendes, O. C., Gobatto, C. A., Campos, E. Z., \& Papoti, M. (2015). Running-based anaerobic sprint test as a procedure to evaluate anaerobic power. International Journal of Sports Medicine, 36(14), 1156-1162. https://doi.org/10.1055/s-0035-1555935

Asadi, A. (2016). Relationship between jumping ability, agility and sprint performance of elite young basketball players: A field-test approach. Revista Brasileira de Cineantropometria \& Desempenho Humano, 18(2), 177-186. https://doi.org/10.5007/1980-0037.2016v18n2p177

Astorino, T. A., Allen, R. P., Roberson, D. W., \& Jurancich, M. (2012). Effect of high-intensity interval training on cardiovascular function, VO2max, and muscular force. The Journal of Strength \& Conditioning Research, 26(1), 138-145. https://doi.org/10.1519/jsc.0b013e318218dd77

Bacon, A. P., Carter, R. E., Ogle, E. A., \& Joyner, M. J. (2013). VO2max trainability and high intensity interval training in humans: A meta-analysis. PloS One, 8(9), 1-7. https://doi.org/10.1371/journal.pone.0073182 
Bagger, M., Petersen, P. H., \& Pedersen, P. K. (2003). Biological variation in variables associated with exercise training. International Journal of Sports Medicine, 24(06), 433-440. https://doi.org/10.1055/s-2003-41180

Batacan, R. B., Duncan, M. J., Dalbo, V. J., Tucker, P. S., \& Fenning, A. S. (2017). Effects of high-intensity interval training on cardiometabolic health: A systematic review and meta-analysis of intervention studies. British Journal of Sports Medicine, 51(6), 494-503. http://dx.doi.org/10.1136/bjsports-2015-095841

Bressel, E., Wing, J. E., Miller, A. I., \& Dolny, D. G. (2014). High-intensity interval training on an aquatic treadmill in adults with osteoarthritis: effect on pain, balance, function, and mobility. The Journal of Strength \& Conditioning Research, 28(8), 2088-2096. https://doi.org/10.1519/jsc.0000000000000258

Brownson, R. C., Baker, E. A., Housemann, R. A., Brennan, L. K., \& Bacak, S. J. (2001). Environmental and policy determinants of physical activity in the United States. American Journal of Public Health, 91(12), 1995-2003. https://doi.org/10.2105/ajph.91.12.1995

Buchan, D. S., Ollis, S., Young, J. D., Cooper, S. M., Shield, J. P., \& Baker, J. S. (2013). High intensity interval running enhances measures of physical fitness but not metabolic measures of cardiovascular disease risk in healthy adolescents. BMC Public Health, 13(1), 498-509. https://doi.org/10.1186/1471-2458-13-498

Charach, G., Rabinovich, P. D., \& Weintraub, M. (2004). Seasonal changes in blood pressure and frequency of related complications in elderly Israeli patients with essential hypertension. Gerontology, 50(5), 315-321. https://doi.org/10.1159/000079130

Chin, S. H., Kahathuduwa, C. N., \& Binks, M. (2016). Physical activity and obesity: what we know and what we need to know. Obesity Reviews, 17(12), 1226-1244. https://doi.org/10.1111/obr.12460

Daniels, J., \& Scardina, N. (1984). Interval training and performance. Sports Medicine, 1(4), 327-334. https://doi.org/10.2165/00007256-198401040-00006

Garber, C. E., Blissmer, B., Deschenes, M. R., Franklin, B. A., Lamonte, M. J., Lee, I. M., Nieman, D. C., et al. (2011). Quantity and quality of exercise for developing and maintaining cardiorespiratory, musculoskeletal, and neuromotor fitness in apparently healthy adults: guidance for prescribing exercise. Medicine \& Science in Sports \& Exercise, 43(7), 1334-1359. https://doi.org/10.1249/mss.0b013e318213fefb

Gribble, P. A., \& Hertel, J. (2003). Considerations for normalizing measures of the Star Excursion Balance Test. Measurement in Physical Education and Exercise Science, 7(2), 89-100. https://doi.org/10.1207/s15327841mpee0702_3

Gunay, M., Tamer, K., Cicioglu, I., Cevik, C. (2000). The effect of two different types of interval training programs on some physiological parameters. Ege University Journal of Sports Medicine, 35(4), 139-146.

Gutin, B., Barbeau, P., Owens, S., Lemmon, C. R., Bauman, M., Allison, J., ... Litaker, M. S. (2002). Effects of exercise intensity on cardiovascular fitness, total body composition, and visceral adiposity of obese adolescents. The American Journal of Clinical Nutrition, 75(5), 818-826. https://doi.org/10.1093/ajcn/75.5.818

Howard, N., \& Stavrianeas, S. (2017). In-season high-intensity interval training improves conditioning in high school soccer players. International Journal of Exercise Science, 10(5), 713-720.

Iacono, A. D., Eliakim, A., \& Meckel, Y. (2015). Improving fitness of elite handball players: small-sided games vs. high-intensity intermittent training. The Journal of Strength \& Conditioning Research, 29(3), 835-843. https://doi.org/10.1519/jsc.0000000000000686

Kaplan, T., Taşkın, H., \& Akgül, M. Ş. (2016). Relationship between age, height, weight and speed, acceleration, vertical jump in child soccer players 9-13 ages. International Journal of Sport Culture and Science, 4(Special Issue 1), 31-38. https://doi.org/10.14486/intjscs531

Khammasi, M., Ouerghi, N., Hadj-Taieb, S, S., Feki, M., Thivel, D., \& Boussida, A. (2018). Impact of a 12week high-intensity interval training without caloric restriction on body composition and lipid profile in sedentary healthy overweight/obese youth. Journal of Exercise Rehabilitation, 14(1), 118-125. https://doi.org/10.12965/jer.1835124.562

Kilit, B., \& Arslan, E. (2019). Effects of high-intensity interval training vs. on-court tennis training in young tennis players. The Journal of Strength \& Conditioning Research, 33(1), 188-196. https://doi.org/10.1519/jsc.0000000000002766

Kordi, M., Choopani, S., Hemmatinafar, M., \& Choopani, Z. (2013). The effects of the six week high intensity interval training (HIIT) on resting plasma levels of adiponectin and fat loss in sedentary young women. 
Journal of Jahrom University of Medical Sciences, 11(1), 20-27. https://doi.org/10.29252/jmj.11.1.4

Krishnan, A., Sharma, D., Bhatt, M., Dixit, A., \& Pradeep, P. (2017). Comparison between standing broad jump test and wingate test for assessing lower limb anaerobic power in elite sportsmen. Medical Journal Armed Forces India, 73(2), 140-145. https://doi.org/10.1016/j.mjafi.2016.11.003

Laaksonen, D. E., Lakka, H. M., Salonen, J. T., Niskanen, L. K., Rauramaa, R., \& Lakka, T. A. (2002). Low levels of leisure-time physical activity and cardiorespiratory fitness predict development of the metabolic syndrome. Diabetes Care, 25(9), 1612-1618. https://doi.org/10.2337/diacare.25.9.1612

Laursen, P. B., \& Jenkins, D. G. (2002). The scientific basis for high-intensity interval training. Sports Medicine, 32(1), 53-73. https://doi.org/10.2165/00007256-200232010-00003

MacDougall, J. D., Hicks, A. L., MacDonald, J. R., McKelvie, R. S., Green, H. J., \& Smith, K. M. (1998). Muscle performance and enzymatic adaptations to sprint interval training. Journal of applied physiology, 84(6), 2138-2142. https://doi.org/10.1152/jappl.1998.84.6.2138

Milanović, Z., Sporiš, G., \& Weston, M. (2015). Effectiveness of high-intensity interval training (HIT) and continuous endurance training for VO 2 max improvements: a systematic review and meta-analysis of controlled trials. Sports Medicine, 45(10), 1469-1481. https://doi.org/10.1007/s40279-015-0365-0

Miller, M. B., Pearcey, G. E. P., Cahill, F., McCarthy, H., Stratton, S. B. D., Noftall, J. C., ... Button, D. C. (2014). The effect of a short-term high-intensity circuit training program on work capacity, body composition, and blood profiles in sedentary obese men: A pilot study. BioMed Research International, 2014, 1-10. https://doi.org/10.1155/2014/191797

Monks, L., Seo, M. W., Kim, H. B., Jung, H. C., \& Song, J. K. (2017). High-intensity interval training and athletic performance in Taekwondo athletes. The Journal of Sports Medicine and Physical Fitness, 57(10), 1252-1260. https://doi.org/10.23736/s0022-4707.17.06853-0

Naimo, M. A., De Souza, E. O., Wilson, J. M., Carpenter, A. L., Gilchrist, P., Lowery, R. P., ... Joy, J. (2015). High-intensity interval training has positive effects on performance in ice hockey players. International Journal of Sports Medicine, 36(01), 61-66. https://doi.org/10.1055/s-0034-1382054

Ockene, I. S., Chiriboga, D. E., Stanek III, E. J., Harmatz, M. G., Nicolosi, R., Saperia, G., ... Hebert, J. R. (2004). Seasonal variation in serum cholesterol levels: Treatment implications and possible mechanisms. Archives of internal medicine, 164(8), 863-870. https://doi.org/10.1001/archinte.164.8.863

Rodas, G., Ventura, J. L., Cadefau, J. A., Cussó, R., \& Parra, J. (2000). A short training programme for the rapid improvement of both aerobic and anaerobic metabolism. European journal of applied physiology, 82(5-6), 480-486. https://doi.org/10.1007/s004210000223

Ryan, A. S., Pratley, R. E., Goldberg, A. P., \& Elahi, D. (1996). Resistive training increases insulin action in postmenopausal women. The Journals of Gerontology Series A: Biological Sciences and Medical Sciences, 51(5), 199-205. https://doi.org/10.1093/gerona/51a.5.m199

Segal, N. A., Hein, J., \& Basford, J. R. (2004). The effects of Pilates training on flexibility and body composition: An observational study. Archives of Physical Medicine and Rehabilitation, 85(12), 1977-1981. https://doi.org/10.1016/j.apmr.2004.01.036

Seo, M. W., Lee, J. M., Jung, H. C., Jung, S. W., \& Song, J. K. (2019). Effects of various work-to-rest ratios during high-intensity interval training on athletic performance in adolescents. International Journal of Sports Medicine, 40(08), 503-510. https://doi.org/10.1055/a-0927-6884

Sequeira, S., Cruz, C., Pinto, D., Santos, L., \& Marques, A. (2011). Prevalence of barriers for physical activity in adults according to gender and socioeconomic status. British Journal of Sports Medicine, 45(15), A18-A19. https://doi.org/10.1136/bjsports-2011-090606.59

Shook, R. P. (2016). Obesity and energy balance: What is the role of physical activity? Expert Review of Endocrinology \& Metabolism, 11(6), 511-520. https://doi.org/10.1080/17446651.2016.1243465

Simoneau, J. A., Lortie, G., Boulay, M. R., Marcotte, M., Thibault, M. C., \& Bouchard, C. (1987). Effects of two high-intensity intermittent training programs interspaced by detraining on human skeletal muscle and performance. European journal of applied physiology and occupational physiology, 56(5), 516-521. https://doi.org/10.1007/bf00635363

Stavrinou, P. S., Bogdanis, G. C., Giannaki, C. D., Terzis, G., \& Hadjicharalambous, M. (2019). Effects of high-intensity interval training frequency on perceptual responses and future physical activity participation. 
Applied Physiology, Nutrition, and Metabolism, 44(9), 952-957. https://doi.org/10.1139/apnm-2018-0707

Szmedra, L., Lemura, L. M., \& Shearn, W. M. (1998). Exercise tolerance, body composition and blood lipids in obese African-American women following short-term training. The Journal of Sports Medicine and Physical Fitness, 38(1), 59-65.

Trost, S. G., Owen, N., Bauman, A. E., Sallis, J. F., \& Brown, W. (2002). Correlates of adults' participation in physical activity: review and update. Medicine \& Science in Sports \& Exercise, 34(12), 1996-2001. https://doi.org/10.1097/00005768-200212000-00020

Verheggen, R. J. H. M., Maessen, M. F. H., Green, D. J., Hermus, A. R. M. M., Hopman, M. T. E., \& Thijssen, D. H. T. (2016). A systematic review and meta-analysis on the effects of exercise training versus hypocaloric diet: distinct effects on body weight and visceral adipose tissue. Obesity Reviews, 17(8), 664-690. https://doi.org/10.1111/obr.12406

Weston, K. S., Wisløff, U., \& Coombes, J. S. (2014). High-intensity interval training in patients with lifestyle-induced cardiometabolic disease: a systematic review and meta-analysis. British Journal of Sports Medicine, 48(16), 1227-1234. https://doi.org/10.1136/bjsports-2013-092576

\section{Copyrights}

Copyright for this article is retained by the author(s), with first publication rights granted to the journal.

This is an open-access article distributed under the terms and conditions of the Creative Commons Attribution license (http://creativecommons.org/licenses/by/4.0/). 